\title{
«MEDIDAS DE REGENERACIÓN DEMOCRÁTICA». LA NUEVA REGULACIÓN DE LA FINANCIACIÓN DE LOS PARTIDOS POLÍTICOS EN ESPAÑA
}

\author{
Inés Olaizola Nogales ${ }^{1}$
}

\begin{abstract}
Sumario: 1. Introducción. 2. La Ley ORgánica 3/2015, De 30 DE MARZO DE CONTROL DE LA ACTIVIDAD FINANCIERA DE LOS PARTIDOS POLÍTICOS (LOFPP). 2.1. Regulación de la transparencia y del control en la LOFPP. 2.2. Régimen de infracciones y sanciones en la LOFPP. 2.3. Conclusiones sobre la LOFPP. 3. LOS NUEVOS DELITOS DE FINANCIACIÓN ILEGAL INTRODUCIDOS POR LA LEY ORGÁNICA 1/2015, DE 30 DE MARZO POR LA QUE SE MODIFICA LA LEY ORGÁNICA 10/1995, DE 23 DE Noviembre de Código Penal. 3.1. Consideraciones previas. 3.2. Bien jurídico protegido y aclaración de conceptos. 3.2.1. Bien jurídico. 3.2.2. Aclaración de conceptos: financiación irregular, financiación ilegal y financiación corrupta. 3.3. Preceptos concretos y valoración crítica. 4. Propuesta PERSONAL DE REGULACIÓn PENAL. 4.1. Supuestos en los que se ve involucrada la Administración. 4.2. Supuestos en los que no se ve involucrada la Administración.
\end{abstract}

\section{INTRODUCCIÓN}

El control de la financiación de los partidos políticos en España es una cuestión sin resolver a pesar de haber sido el origen de muchos y variados

${ }^{1}$ El trabajo se inserta en el Proyecto de investigación financiado por MINECO DER2013-47511-R, dirigido por el prof. Miguel Díaz y García ConLLedo, de cuyo equipo investigador formo parte. 
escándalos de corrupción y haber afectado a casi todas las formaciones políticas $^{2}$. Así lo afirma con contundencia el GRECO en el informe adoptado en la $42^{\text {a }}$ Reunión Plenaria (15 de mayo de 2009) y hecho público el 28 de mayo de 2009 y se vuelve a poner de relevancia como problema en el Informe de la Comisión Europea de 3 de febrero de 2014 3 .

En el presente trabajo trataré de analizar las últimas reformas legislativas relacionadas con la financiación de los partidos políticos. Concretamente LO 3/2015, de 30 de marzo, de control de la actividad económico-financiera de los partidos políticos (LOFPP) así como la LO 1/2015, de 30 de marzo -con entrada en vigor el 1 de julio-, por la que se modifica el CP, e incorpora la tipificación autónoma del delito de financiación ilegal de los partidos políticos.

2 Septiembre de 1984: adjudicaciones irregulares de contratas de limpieza por parte de ayuntamientos del PSOE a empresas desde donde se recaudaban importantes cantidades de fondos para el partido; Noviembre de 1984: Escándalo Flick en el que se acusaba al PSOE de haber recibido dinero negro procedente de fundaciones alemanas; Diciembre 1989: desvío de unos 3.000 millones de pesetas de la recaudación de casinos en Cataluña, de los que aproximadamente unos mil habrían ido a la financiación de CIU; Marzo de 1990: caso de las tragaperras en el que se concedían licencias de máquinas tragaperras sin seguir los cauces legales a cambio de comisiones que presuntamente en parte sirvieron para la financiación del PNV; Abril de 1990: caso Naseiro en el que se descubren indicios de que desde el PP se fuerza a empresas inmobiliarias a pagar al PP para poder construir; Mayo 1991: caso Filesa en este caso tres empresas cobraron importantes cantidades de dinero en concepto de asesoramiento para destacadas empresas y bancos que nunca llegaron a realizarse, el dinero servía para financiar al PSOE; mayo 1992: caso AVE desglosado del caso Filesa donde se investigaron presuntas comisiones pagadas en la construcción de la línea de alta velocidad Madrid-Sevilla, estas comisiones sirvieron para la financiación del PSOE; Mayo de 1995: caso Sóller en el que hubo presuntos cobros de comisiones a la empresa adjudicataria del contrato de construcción del túnel Sóller, comisiones que se dedicaron a la financiación del PP. 2003: caso del 3\%, en un debate en el Parlamento Catalán, el entonces Presidente de la Generalitat, Pasqual Maragall insinuó que el anterior gobierno de CIU cobraba comisiones del 3\% a las empresas adjudicatarias de contratos de construcción; 2009: caso Gürtel, actualmente en proceso de investigación, se prevé que sea uno de los casos más importantes de corrupción de los relacionados con la financiación ilegal. Se trata básicamente de una trama de cobro de comisiones ilegales a empresas a cambio de adjudicaciones para la financiación del PP. 2013: caso Bárcenas es un derivado del caso Gürtel en el que el tesorero del PP pagaba presuntamente sobresueldos a altos cargos del PP que provenían a su vez de comisiones pagadas por empresas que resultaban adjudicatarias de contratos con la Administración. De dichas comisiones Bárcenas se fue quedando presuntamente con cantidades importantes; 2013: el denominado caso Pallerols por financiación ilegal de Convergencia de Cataluña en el que presuntamente se cobraron más de seis millones de euros de comisiones de distintas empresas.

${ }^{3}$ Informe del GRECO de Evaluación sobre transparencia en la Financiación de partidos políticos en España. Informe de lucha contra la corrupción de la UE de 3 de febrero de 2014. 
Como consideración previa en la que no me extenderé, porque ya la he analizado en otro trabajo ${ }^{4}$, puedo afirmar que el modelo de financiación público, privado o mixto, este último es el modelo español, no influye decisivamente en una mayor o menor corrupción. Lo que sí creo necesario es la articulación de requisitos y de límites, para evitar riesgos cualquiera que sea el modelo. Todos los modelos de financiación tienen unas ventajas y algunos inconvenientes. Así, por ejemplo, la financiación pública tiene la ventaja de que permite a todos los partidos políticos acceder a la arena del juego político, pero tiene la desventaja de que una financiación pública excesiva puede alejar a los partidos de los ciudadanos, puesto que no les necesitan y puede llevar a una importante oligarquización de los partidos. Al contrario, la financiación privada tiene como ventaja la mayor conexión entre los partidos y los ciudadanos, puesto que son ellos quienes les financian, pero se ve el peligro de que las formaciones políticas queden atrapadas por determinados intereses privados (grupos empresariales). En el informe de la Comisión Europea de 3 de febrero de 2014 se reconoce que, si bien en España se han realizado pocos estudios sobre los riesgos asociados a los grupos de presión, los recientes casos de corrupción indican la influencia potencial en la toma de decisiones a nivel local y regional de determinados grupos de interés relacionados con los sectores del urbanismo y de la construcción ${ }^{5}$. Es importante, por tanto establecer los límites tanto para un modelo como para el otro, para evitar los riesgos asociados a ellos.

En mi opinión, no obstante, son otras las causas que facilitan las conductas corruptas en este ámbito ${ }^{6}$. Así, el elevado y descontrolado gasto de los partidos políticos, tanto gastos electorales como gastos ordinarios, que, por cierto, se entremezclan haciendo difusa la frontera entre unos y otros, pero estando sin embargo regulados por diferente normativa. Otra posible causa es el bajo índice de afiliados. Según el informe del GRECO de 2009 somos el país de Europa con menor índice de afiliados, lo que, además de reflejar el importante desapego entre los ciudadanos y los grupos políticos, lleva aparejado un escaso nivel de esta fuente de financiación. La tercera causa sería la falta de transparencia en la financiación de los partidos, derivada de las dificultades de fiscalización y de control de sus cuentas. Sobre este tema volveré

${ }^{4}$ Olaizola nogales, I., La financiación ilegal de los partidos políticos, 2014, pp. 91 ss.

5 Informe de lucha contra la corrupción de la UE (Anexo España), de 3 de febrero de 2014. En el informe se hace especial referencia a las investigaciones en las que están implicados un ex tesorero de un partido político y casi noventa destacados políticos, empresarios y banqueros acusados de prácticas corruptas relacionadas con la contratación pública y la financiación ilegal de los partidos -clara alusión al caso Gürtel-.

${ }_{6}$ Ampliamente, olaizola nogales, I., La financiación ilegal de los partidos politicos, op. cit., pp. 102 ss. 
más adelante cuando analice las mejoras introducidas por la LOFPP en este aspecto. Como cuarta causa se puede señalar la excesiva discrecionalidad y ausencia de controles en algunos ámbitos de la actividad administrativa, concretamente en el sector urbanístico y en la contratación pública.

\section{LA LO 3/2015, DE 30 DE MARZO, DE CONTROL DE LA ACTIVIDAD ECONÓMICO-FINANCIERA DE LOS PARTIDOS POLÍTICOS (LOFPP)}

La LO 3/2015 modifica la LO 8/2007 de financiación de partidos políticos, que ya había sido modificada parcialmente por la LO 5/2012.

Esta LOFPP trata fundamentalmente de dar respuesta a algunas recomendaciones efectuadas por el GRECO en su informe de 2009, así como a las indicaciones efectuadas por el Tribunal de Cuentas en la moción aprobada por el 30 de octubre de 2001, a las que la LO 8/2007 y su reforma la LO $5 / 2012$ no dieron respuesta.

Sin embargo, lo más comentado de esta LO ha sido la prohibición que se prevé para las donaciones de las personas jurídicas a los partidos políticos. Esta prohibición precisamente no ha sido recomendada ni por el Tribunal de Cuentas ni por el GRECO y a mi modo de ver, más allá de que genere un titular políticamente rentable, no es una buena decisión. Si bien es cierto que las donaciones provenientes de empresas pueden beneficiar a aquellos partidos con mayores conexiones ideológicas con los grupos empresariales y también puede existir el peligro de que se produzca lo que se denomina la captura del legislador, también es verdad que prohibir estas donaciones no las eliminará y únicamente las ocultará. Yo creo que estos peligros pueden neutralizarse si se adoptan algunas precauciones ${ }^{7}$. Así, las donaciones deben ser publicitadas para que los ciudadanos puedan hacer un seguimiento continuo del comportamiento de los partidos con sus donantes; es muy importante evitar las donaciones finalistas, para ello parece imprescindible modificar alguna normativa relacionada con la contratación pública y reducir el nivel de discrecionalidad de este ámbito; deben prohibirse también las donaciones de empresas públicas, las donaciones de contratistas de de obras y servicios públicos que tengan contrato vigente con la Administración, así como de empresas de sectores regulados especialmente dependientes de decisiones político-administrativas, empresas promotoras de suelo y vivienda respecto de las autoridades urbanísticas; también deben controlarse los préstamos concedidos por las entidades de crédito a los partidos y se deben prohibir las condonaciones; por último debe limitarse la cuantía máxima de las donacio-

\footnotetext{
${ }^{7}$ Extensamente, ibidem, pp. 95 ss.
} 
nes para que ninguna empresa o grupo empresarial pueda ejercer una influencia excesiva sobre un partido político. Considero que con estos límites las donaciones de empresas serán más transparentes y controlables y se conjurarán los posibles peligros. Al contrario, prohibiéndolas lo que se generarán serán donaciones ocultas y fuera de control.

Más allá de esta prohibición, la LO 3/2015 presenta más novedades y se puede dividir su análisis en dos partes. Por un lado, aquellos preceptos que están relacionados con el fomento de la transparencia y del control y por otro lado, los que recogen el régimen sancionador.

\subsection{Regulación de la transparencia y del control en la LOFPP}

La LO 5/2012 mejoró, en cuanto a transparencia se refiere, la anterior LO $8 / 2007$. Así, en concreto se indica que las donaciones privadas deben abonarse en cuentas de entidades de crédito abiertas exclusivamente para dicho fin. Además, debe señalarse la fecha de imposición, el importe de la donación y la identidad del donante; las donaciones superiores a 50.000 euros y en todo caso las donaciones de bienes inmuebles deben ser notificadas al Tribunal de Cuentas en un plazo máximo de tres meses ${ }^{8}$. También las cuotas y aportaciones de los afiliados o simpatizante deberán abonarse en cuentas de entidades de crédito abiertas exclusivamente para dicho fin y también deberá constar la fecha, el importe y la identidad del donante. Los partidos políticos deben llevar libros de contabilidad detallados. Deben presentar las cuentas anuales correspondientes a cada ejercicio económico ante el Tribunal de Cuentas y una vez emitido el informe por el Tribunal de Cuentas, los partidos políticos están obligados a hacer públicas, preferentemente a través de su página web, el balance y la cuenta de resultados, la cuantía de los créditos concedidos, el tipo de entidad concedente y las condonaciones de deuda correspondientes al ejercicio. Esta publicación debe ser de acceso gratuito y fácil para los ciudadanos. Los partidos políticos deben dar cuenta al Tribunal de Cuentas y al Banco de España de los acuerdos que lleguen con las entidades de crédito sobre las condiciones de la deuda que mantengan con ellas. Los partidos políticos deben prever un sistema de control interno y deben rendir cuentas externamente ante el Tribunal de Cuentas ${ }^{9}$. También se incorporan algunas

${ }^{8}$ En las donaciones en especie se acreditará también la entrega del bien donado haciendo mención expresa al carácter irrevocable de la donación.

9 Por lo que se refiere a la Ley Orgánica 5/1985 de Régimen Electoral General también requiere una contabilidad detallada de las campañas electorales. Los partidos políticos tendrán que contratar un «administrador electoral» para que gestione las finanzas relacionadas con la campaña. Hay que abrir una cuenta específica para la campaña a través de la que se canalizan todas las donaciones. Las donaciones tendrán que tener la identifi- 
medidas de transparencia relacionadas con las fundaciones y asociaciones vinculadas a los partidos políticos. Así, igual que los partidos políticos, las fundaciones y asociaciones deberán, una vez emitido el informe de fiscalización del Tribunal de Cuentas, hacer públicas, preferentemente a través de su página web, el balance y la cuenta de resultados. Además, están obligadas a informar anualmente al Ministerio de Hacienda de todas las donaciones y aportaciones recibidas y deberán informar en un plazo de tres meses al Tribunal de Cuentas de todas las donaciones provenientes de personas jurídicas.

A pesar de estas medidas, tanto el Tribunal de Cuentas, como el informe del GRECO de 2009 observaban carencias algunas de las cuales no fueron resueltas por la LO 5/2012.

a) Se recomendaba, a efectos de control de la financiación, que el partido político se concibiera como una unidad territorial e institucional, debiendo incluirse en sus estados financieros las cuentas de toda la organización -a nivel estatal, autonómico, regional y local- como, en su caso, las cuentas de las fundaciones vinculadas a los partidos. Debe tenerse en cuenta que las cuentas locales de los partidos políticos no se consolidan con las cuentas estatales, autonómicas y regionales, quedando fuera de control. Esto, como es lógico genera un enorme peligro de corrupción, máxime si se tiene en cuenta las competencias que en materia de urbanismo tienen los entes locales. Por otro lado, también existe un importante riesgo de que las entidades vinculadas a los partidos (fundaciones) asumieran sus gastos, a través de un trasvase ilegal de dinero.

Esta recomendación no fue atendida por la LO 5/2012, pero sí es tenida en cuenta parcialmente por la LO 3/2015. Así, en su art. 14.5 se reconoce que las cuentas consolidadas de los partidos políticos se extenderán a los ámbitos estatal, autonómico y provincial y añade que las cuentas correspondientes al ámbito local y comarcal, si existiese, se integrarán en las cuentas de nivel provincial ${ }^{10}$.

Sin embargo respecto de las cuentas de las fundaciones no se menciona que dichas cuentas tengan que presentarse de manera conjunta con las de los partidos. Sí que se señala en la Disposición adicional séptima que las aportaciones que reciban las fundaciones y entidades vinculadas a los partidos estarán sometidas a los mecanismos de control

cación del donante. Una vez terminada la campaña electoral los administradores electorales presentarán en los 100-125 días siguientes un informe económico detallado de ingresos y gastos ante el Tribunal de Cuentas.

${ }_{10}$ Conforme a la Disposición transitoria tercera los partidos políticos dispondrán de un año desde la entrada en vigor del art. 14 de la LO 8/2007 en su nueva redacción para consolidar sus cuentas a nivel local. Este art. 14 entrará en vigor el 1 de enero de 2016. 
y fiscalización y al régimen sancionador previsto en la ley. Sobre la regulación relativa a las fundaciones volveré más abajo.

b) Otra recomendación venía relacionada con el control de los préstamos otorgados a los partidos por las entidades bancarias. Por un lado se pedía control y límites sobre las condonaciones de los bancos a los partidos y por otro, que se tomaran las medidas adecuadas para controlar las condiciones en que se otorgaban los créditos, así como las cantidades prestadas, puesto que un excesivo nivel de endeudamiento podía hacer que los partidos se volvieran vulnerables/dependientes de las entidades de crédito. El Tribunal de Cuentas señaló en al año 2012 que la deuda total de los partidos políticos (de ámbito nacional y autonómico) con entidades financieras ascendía a 227 millones de euros en $2007^{11}$. Ya la LO 5/2012 limitó la posibilidad de condonación de deudas bancarias a 100.000 euros anuales. En el art. 4.4 LOFPP se aborda el tema de manera relevante. Por un lado, y de forma acertada a mi modo de ver, se prohíben todas las condonaciones de las entidades de crédito a los partidos. Entiendo que es una prohibición positiva, porque no se entiende con qué fundamento pueden justificarse dichas condonaciones, mientras que con ellas se puede generar el peligro de que el partido quede «capturado» por la entidad bancaria. Por otro lado, el art. 4.4. señala que los partidos políticos podrán llegar a acuerdos respecto de las condiciones de la deuda que mantengan con las entidades de crédito, por lo que se mantiene la posibilidad de obtener créditos ventajosos, pero deberán informar de tales acuerdos al Tribunal de Cuentas y al Banco de España y además el tipo de interés acordado no podrá ser inferior al que corresponda según las condiciones de mercado. Además, el art. 14.3 de la LOFPP indica que las cuentas anuales deben acompañarse de una memoria explicativa del Balance y de la Cuenta de Resultados y se acompañará en todo caso de un anexo donde se especifiquen pormenorizadamente las condiciones contractuales estipuladas de los créditos de cualquier clase que el partido mantenga con las entidades de crédito. El incumplimiento de estos deberes supondrá una infracción muy grave del art. 17. Sobre el régimen de infracciones y sanciones volveré más abajo.

c) Otra recomendación tenía que ver con la falta de transparencia de los ingresos y gastos de las fundaciones vinculadas a los partidos políticos, en el sentido de que dichas entidades debían someterse a un mayor control. Conforme a la LO 8/2007 el régimen de financiación de

11 Tribunal de Cuentas, Informe de fiscalización de los estados contables de los partidos políticos y de las donaciones percibidas por las fundaciones vinculadas orgánicamente, ejercicio 2007, informe aprobado el 29 de marzo de 2012. 
las fundaciones vinculadas a los partidos políticos es un tanto especial. Por un lado, en los Presupuestos Generales del Estado se regula la posibilidad de conceder subvenciones a «las fundaciones de partidos políticos de ámbito estatal y con representación parlamentaria». Por otro lado, conforme a la Disposición adicional séptima de la LO $5 / 2012$, no habrá límite cuantitativo para las donaciones privadas otorgadas a las fundaciones, esto es, no están sometidas al límite de los 100.000 euros al que están sometidos lo partidos. Únicamente se prevé que si la donación es superior a 120.000 euros deberán formalizarse en un documento público. También se permite que estas fundaciones reciban donaciones de empresas que tengan contrato vigente con la Administración, situación prohibida para los partidos políticos. En la Disposición adicional séptima de la LOFPP se define qué se entiende por fundaciones y entidades vinculadas a partidos políticos o dependientes de ellos lo que supone una aclaración de conceptos; se obliga a las fundaciones vinculadas a inscribirse en el Registro de Partidos como requisito para recibir subvenciones y se recoge la competencia del Tribunal de Cuentas para fiscalizar la actividad económica-financiera de las fundaciones. Sin embargo sigue manteniéndose la ausencia de límites en cuanto a la cantidad de la donación y se permite la donación de persona jurídica. Se puede afirmar que el régimen financiero de las fundaciones sigue siendo muy especial ${ }^{12}$.

d) Otra recomendación del Tribunal de Cuentas, refrendada por el GRE$\mathrm{CO}$ iba en el sentido de introducir la obligación de que tanto los partidos como las fundaciones y asociaciones vinculadas hicieran públicas, a través de su página web, el balance, la cuenta de resultados, los créditos concedidos, la entidad concedente o las condonaciones. El art. 14.8 de la LO 5/2012 haciendo caso de esta recomendación introdujo la obligación de realizar esa publicación una vez emitido el informe del Tribunal de Cuentas. En la LOFPP se mejora esta previsión porque se exige que la publicación por parte de los partidos se produzca en el plazo máximo de un mes desde la fecha del envío al Tribunal de Cuentas. Esto supone una enorme mejora en cuanto a transparencia, porque, teniendo en cuenta el retraso con el que actúa el Tribunal de Cuentas, la publicación después de la emisión de su informe podía demorarse mucho y por tanto resultar bastante inútil para los ciudadanos. Se introduce además la exigencia de que en la página web se publique las donaciones recibidas por los partidos superiores a 25.000 euros con referencia concreta a la identidad del donante. Esta última

\footnotetext{
${ }^{12}$ En el mismo sentido, SANDOVAL, RGDP 22 (2014), 33.
} 
previsión es muy importante para que los ciudadanos puedan saber quién o quiénes son los financiadores de un partido político. En el caso de las fundaciones, estas deberán publicar en su página web únicamente el balance y la cuenta de resultados, así como las conclusiones del informe de auditoría y dicha publicación se hará una vez emitido el informe del Tribunal de Cuentas.

e) Otra recomendación importante relacionada con la transparencia era la de la unificación del sistema de auditoría interna de los partidos, ya que se dejaba a criterio de cada partido cómo organizar su supervisión interna. La carencia se mantiene en el art. 15 LO 5/2012, donde se indica que el control interno debe articularse conforme a los Estatutos del partido. En la LOFPP no cambia el sistema, puesto que el art. 15 no se modifica. Ahora bien, el art. 14 de la LOFPP introduce una serie de obligaciones relativas a la contabilidad de los partidos políticos que desciende a un gran nivel de detalle en las indicaciones de lo que los partidos deben reflejar en sus libros de contabilidad de manera que estos libros permitan en todo momento conocer la situación financiera y patrimonial del partido. Estas obligaciones contables no se refieren, sin embargo, a las fundaciones. Por otra parte, en el art. 14 bis se recoge, como novedad, la figura del responsable de la gestión económicafinanciera que será una persona con suficientes conocimientos y se responsabilizará de la regularidad de las cuentas anuales.

f) En cuanto al control externo de los partidos es importante destacar la incorporación en la LOFPP de un control parlamentario, recogido en el art. 16 bis, conforme al cual el responsable de la gestión económicofinanciera deberá comunicar anualmente al presidente de la Comisión Mixta para la Relaciones con el Tribunal de Cuentas, la remisión de la documentación contable al Tribunal. Además, la Comisión Mixta podrá solicitar la comparecencia del responsable en el plazo de dos meses desde la aprobación del informe de fiscalización por el Tribunal de Cuentas para que informe sobre su contabilidad. La medida es positiva sin lugar a dudas, porque refuerza el control externo a través del Parlamento. El problema es el de siempre, el retraso tan grande con el que actúa el Tribunal de Cuentas y que puede hacer que la comparecencia del responsable del partido se demore en el tiempo.

g) Otras cuestiones relacionadas con la transparencia que incorpora la LOFPP tienen que ver con la claridad de las cuentas donde se ingresan las donaciones. Tanto las donaciones de particulares como las cuotas de los afiliados deberán ingresarse en cuentas específicas (hasta aquí igual que en la LO 5/2012), pero la novedad reside, en el caso de las donaciones, en que las entidades de crédito deberán informar anualmente al Tribunal de Cuentas sobre las donaciones que hayan sido 
ingresadas en dichas cuentas y en el caso de las cuotas de los afiliados, deberán se ingresadas mediante domiciliación bancaria de una cuenta de la cual sea titular el afiliado, o mediante ingreso nominativo en la cuenta que designe el partido.

\subsection{Régimen de infracciones y sanciones en la LOFPP}

Aunque la LO 8/2007 y posteriormente la LO 5/2012 supusieron una mejora clara respecto a la LO 3/1987, que no preveía ningún régimen sancionador, el Tribunal de Cuentas y el GRECO también hicieron varias recomendaciones relacionadas con la necesidad de estructurar y regular un régimen sancionador adecuado.

Una de las novedades básicas introducida por la LO 8/2007 fue la regulación en su Título VI del régimen sancionador. Los artículos 17 y 18, mejorados por la LO 5/2012 pretenden desarrollar un régimen sancionador completo. El art. 17 recoge las infracciones y sus correspondientes sanciones e indica un plazo de cuatro años para la prescripción de las infracciones. El art.18 articula el procedimiento sancionador y de recursos y el art. 19 incorpora un deber de colaboración con el Tribunal de Cuentas tanto para los partidos políticos como para las entidades que hubieran tenido relaciones de naturaleza económica con los partidos.

En cuanto a las infracciones se catalogan todas como muy graves. La primera, recogida en la letra a) del art. 17.1, considera infracción la contravención de las limitaciones y requisitos establecidos en los arts. 5 y 7 de la Ley, esto es, los referidos a las donaciones anónimas, finalistas, revocables, las aportaciones de las personas extranjeras, así como los relacionados con los límites cuantitativos de la donación. Se equipara en cuanto a infracción y sanción la asunción, por terceras personas, de los gastos del partido en los términos indicados en la ley. La sanción correspondiente a esta infracción viene indicada a continuación y consiste en la imposición por el Tribunal de Cuentas de una sanción de cuantía equivalente al doble de la aportación ilegalmente percibida.

La segunda infracción se recoge en el art. 17.1 b) y consiste en no presentar las cuentas anuales ante el Tribunal de Cuentas o que se presenten de manera tan deficiente que el Tribunal no pueda realizar su labor fiscalizadora. La sanción consiste en la retención de la subvención anual hasta que se cumpla con el deber de rendición o se subsanen los defectos.

La tercera y última infracción tipificada consiste, sin perjuicio de lo establecido en la LOREG a la que luego haré referencia, en la superación de los límites de gastos electorales.

Entre las recomendaciones más importantes destacan: 
a) El GRECO en su informe de 2009 recomendaba que las infracciones se tipificaran al menos según su gravedad y que las sanciones se graduaran según la gravedad de las infracciones. También recomendaba la introducción de eximentes, atenuantes y agravantes. En mi opinión, el catálogo de las infracciones recogidas en el art. 17 LO 5/2012 resulta poco detallado y escaso, dejando fuera algunas conductas graves, tales como la no apertura de cuentas específicas para las donaciones, la no publicación en la página web de las cuentas o la recepción de donaciones provenientes de empresas públicas, entre otras.

Esta situación mejora claramente en la LOFPP. El nuevo art. 17 diferencia entre infracciones muy graves, estas serán: a) las que contravengan los límites relacionados con las cantidades de las donaciones, su carácter anónimo, finalista o revocable, también la asunción por parte de un tercero de los gastos del partido. También constituirán infracciones muy graves la aceptación de donaciones que provengan de personas jurídicas o de gobiernos extranjeros o los acuerdos sobre condiciones de deuda que infrinjan la prohibición contenida en el art. 4.4. En estos casos la sanción será, conforme al art. 17 bis, una multa del doble al quíntuplo de la cantidad que exceda del límite, de la cantidad asumida por un tercero o de la cantidad condonada También será muy grave: b) la superación en un diez por ciento o más de los límites de los gastos electorales, en cuyo caso la sanción será una multa del duplo al quíntuplo del exceso producido. Y por último: c) el incumplimiento durante dos ejercicios consecutivos o tres alternos de la obligación de presentar las cuentas anuales en plazo o la presentación de cuentas incompletas o deficientes. En este caso la sanción será de un mínimo de cincuenta mil y un máximo de cien mil euros. Las infracciones graves serán cuatro. La primera consistirá en la realización de actividades mercantiles. En este caso la sanción será una multa entre veinticinco mil y cincuenta mil euros más una multa equivalente al cien por cien del beneficio obtenido. La segunda consistirá en la superación en más de un tres y menos de un diez por ciento de los límites de los gastos electorales, en cuyo caso la sanción será del doble al quíntuplo del exceso de gasto producido. La tercera viene conformada por el incumplimiento de presentar las cuentas anuales o de presentarlas de forma incompleta durante un ejercicio o el incumplimiento de cualquier otra obligación contable. La cuarta infracción grave será la falta de un sistema de auditoria o de control interno. Para la tercera y la cuarta infracción la sanción será de un mínimo de diez mil y un máximo de cincuenta mil euros. Las infracciones leves son dos. La primera consistirá en faltar al deber de colaboración que establece el art. 19, que consiste tanto en el deber de 
colaboración de los partidos con el Tribunal de Cuentas a efectos de remitirle la documentación requerida, como el deber de colaboración de las entidades que tienen relaciones de naturaleza económica con los partidos que también deberán enviar al Tribunal de Cuentas la documentación que les sea requerida, y la segunda será la superación por los partidos en más de un uno y hasta un tres por ciento de los límites de los gastos electorales. La sanción para el primer caso es de multa de entre cinco mil y diez mil euros y en el segundo caso la sanción irá del doble al quíntuplo del exceso de gasto producido.

b) Otra mejora que atiende a las recomendaciones del Tribunal de Cuentas es por tanto la consideración como infracción (leve) del incumplimiento del deber de colaboración. En la LO 5/2012 no sólo no se recoge como infracción tal conducta, sino que al contrario se hace referencia al deber de sigilo que respecto a esta información tienen los miembros del Tribunal de Cuentas y las responsabilidades administrativas o penales derivadas de su incumplimiento.

c) Otra recomendación del GRECO hacía referencia a la conveniencia de introducir como infracción, con la correspondiente sanción, la conducta del donante que realiza una donación ilegal. Esta recomendación no se recoge ni en la LO 5/2012, ni en la LOFPP.

d) Otras cuestiones que mejoran en la LOFPP relacionadas con el régimen sancionador, son la mayor pormenorización del procedimiento sancionador, mucho más detallado en el proyecto, y la diferencia de plazos de prescripción de las infracciones según sean muy graves cinco años-, graves -tres años-y leves -dos años-.

\subsection{Conclusiones sobre la LOFPP}

En mi opinión el PLOFPP supone una mejora respecto de la ley anterior, la LO 8/2007, modificada por la LO 5/2012 de financiación de partidos políticos. Como se ha visto, atiende en gran medida a las recomendaciones del Tribunal de Cuentas y del GRECO y ello es positivo. Mejora tanto en el nivel de transparencia exigible como en el régimen de infracciones y sanciones. Así lo reconoce también el informe lucha contra la corrupción elaborado por la Comisión Europea de fecha 3 de febrero de 2014 ${ }^{13}$.

No obstante, se puede realizar todavía algunas críticas. La primera es que sigue sin regularse con claridad el régimen de financiación de las fundaciones y asociaciones vinculadas a los partidos políticos. Al no exigirse los mismos límites para la financiación de estos entes que para la financiación de

13 También considera que la reforma va en la dirección acertada, SANDOVAL, RGDP 22 (2014), 25. 
los partidos (ni cuantitativos, ni de procedencia, ni de transparencia) se mantiene el peligro de que a través de estas fundaciones se proceda a un trasvase ilegal de dinero a los partidos políticos.

Como segunda crítica, que ya he explicado más arriba, se puede decir que la prohibición de donaciones de empresas a los partidos políticos no supondrá que esta se eliminen, sino que queden ocultas y exentas de controles. No me parece una medida adecuada y tampoco responde a una recomendación ni del Tribunal de Cuentas ni del GRECO.

Como tercera objeción, esta más general, creo que es importante una propuesta de reforma de la LOREG. El Tribunal de Cuentas ha venido reclamando en sus informes que se regule adecuadamente el régimen de control en materia de financiación electoral, pero en las sucesivas reformas de la LOREG se ha hecho caso omiso a estas recomendaciones, por lo que las propuestas siguen teniendo plena vigencia. Es verdad, no obstante que en la Disposición final cuarta de la LOFPP se modifica la LOREG parcialmente y concretamente el art. 134.2 de dicha Ley. Se remite ahora dicho precepto -en los supuestos en los que se hayan superado los límites electorales- a la LO $8 / 2007$, que habrá de entenderse en la nueva redacción dada en este punto al art. 17 por la LO $3 / 2015$.

Convendría realizar una revisión íntegra de de la LOREG e incluso estudiar la posibilidad de incluir toda la regulación sobre la financiación de partidos políticos en una sola norma. También resultaría interesante el estudio sobre la necesidad de diferenciar entre financiación ordinaria y financiación electoral, teniendo en cuenta los límites difusos que separan en muchas ocasiones los gastos electorales de los gastos ordinarios y que en ocasiones los gastos ordinarios sirven para pagar gastos electorales encubiertos.

Entre otras cuestiones, el Tribunal de Cuentas ha propuesto que los partidos políticos tuvieran que rendir cuentas cuando fueran a intervenir en procesos electorales. Conforme a la LO8/2007 la obligación de rendir cuentas se limita únicamente a las formaciones que han obtenido un anticipo de subvenciones públicas en atención a los resultados obtenidos en anteriores elecciones. Es verdad que en el art. 16 LOFPP se añade la posibilidad de que el Tribunal fiscalice las cuentas de todos los partidos y no sólo de los que hubieran recibido subvenciones públicas.

Se considera necesaria también una armonización de las normas electorales, tanto entre las Comunidades Autónomas entre sí, como entre estas y la normativa estatal.

Se entiende imprescindible la aclaración del concepto de gasto electoral y la fijación del límite máximo de gasto autorizado. El Tribunal ha planteado la necesidad de reducir los gastos de propaganda electoral y propone su sustitución por otras técnicas de información. 


\section{LOS NUEVOS DELITOS DE FINANCIACIÓN ILEGAL INTRODUCIDOS POR LA LO 1/2015, DE 30 DE MARZO QUE MODIFICA LA LO 10/1995, DE 23 DE NOVIEMBRE DE CÓDIGO PENAL}

\subsection{Consideraciones previas}

La LO 1/2015, de 30 de marzo, por la que se modifica el CP, introduce los delitos de financiación ilegal de los partidos políticos.

La primera consideración que es conveniente hacer está relacionada con la ubicación de los preceptos. Se incluyen en un nuevo Título XIII bis, justo detrás del Título XIII que contiene los delitos contra el patrimonio y contra el orden socioeconómico. Se puede convenir en que el orden y la ubicación de los preceptos en el CP tienen un sentido a la hora de interpretarlos ${ }^{14}$. En mi opinión, un posible delito de financiación ilegal no guarda ninguna relación con valores de carácter económico. Como se analizará más abajo, si hay algún bien jurídico que merezca ser protegido frente a este tipo de conductas será un bien jurídico relacionado con las funciones constitucionales que cumplen los partidos políticos, por lo que la ubicación de estos preceptos debería ser entre los delitos contra la Constitución. En este sentido recuerda la STC 3/1981, de 2 de febrero que los partidos tienen un status privilegiado frente al resto de asociaciones privadas, gozan de derechos como los de obtener ayuda financiera del Estado o la utilización gratuita de medios públicos de comunicación, pero a cambio tienen la contrapartida de cumplir con su función constitucional de concurrir a la manifestación de la voluntad popular.

La segunda consideración es para recordar que la ausencia de la tipificación autónoma o específica de un delito de financiación ilegal de partidos políticos no implica que muchas de las conductas que se producen en este ámbito no puedan ser sancionables penalmente. Las razones aducidas por los autores para la defensa de una tipificación autónoma son, por un lado, la existencia de lagunas de punibilidad, ya que hay conductas que con los tipos penales actuales no serían punibles, en segundo lugar, la complejidad de los procesos penales al no estar lo suficientemente claro qué tipos penales son aplicables y por último la existencia de un bien jurídico autónomo ${ }^{15}$.

Más allá de las posibles lagunas, que lo serán en la medida en que se considere que tales conductas deben estar tipificadas, y de la complejidad del proceso, independientemente de que haya delitos que se puedan aplicar o no, la razón que me parece importante para valorar si la tipificación autónoma es

${ }^{14}$ LuZÓn Peña, Curso I, 1996, $168 \mathrm{~s}$.

15 Nieto Martín, A., en Arroyo Zapatero, L.A. y Nieto Martin, A., (Coords.), Fraude y corrupción, 2006, pp. 120 ss.; MAROTO CALATAYUD, M., Corrupción y financiación de partidos políticos 2012, pp. 377 ss. (Tesis Doctoral inédita). 
o no necesaria es la tercera, esto es la verificación de si hay o no uno o varios bienes jurídicos específicos merecedores de protección penal.

Según Nieto Martín, la financiación ilegal de partidos lesiona bienes jurídicos autónomos merecedores de protección penal, tales como la transparencia en la financiación, la igualdad de oportunidades entre las distintas fuerzas políticas y la democracia interna dentro de los partidos políticos. Afirma este autor que la igualdad de oportunidades entre las fuerzas políticas y la transparencia patrimonial son requisitos indispensables para que el voto pueda ser verdaderamente responsable y por tanto libre ${ }^{16}$.

En sentido parecido se manifiesta MAROTO CALATAYUD, al afirmar que el injusto específico de la financiación ilegal abarca la alteración del funcionamiento del sistema de partidos, tanto en lo que se refiere a la igualdad de oportunidades entre partidos como a la quiebra de la democracia interna y la oligarquización de las organizaciones políticas que implica ${ }^{17}$.

En mi opinión, el funcionamiento del sistema de partidos en si mismo no constituye un bien jurídico merecedor de protección penal. El criterio para decidir cuándo una conducta de financiación ilegal merece reproche penal y cuándo no, debe venir derivado de las propias funciones constitucionales que ejercen los partidos políticos hacia los ciudadanos. Dichas funciones se recogen en el art. 6 de la Constitución que indica que los partidos políticos expresan el pluralismo político, concurren a la formación y manifestación de la voluntad popular y son instrumento fundamental para la participación política.

Aunque volveré más adelante sobre ello, ya adelanto que el delito de financiación ilegal tendrá sentido sólo para proteger aquellas conductas que, no estando correctamente recogidas en los tipos actuales, perturben aquellas funciones de servicio a los ciudadanos que cumplen los partidos. Los partidos son los instrumentos necesarios para que los ciudadanos puedan participar en la vida política y canalizar a través de ellos sus intereses. Por tanto, no cualquier perturbación de la transparencia financiera de los partidos o de la igualdad entre las fuerzas políticas o de la democracia interna de los partidos será suficiente para ser tipificada penalmente a través de un tipo autónomo, sino que se sancionarán penalmente aquellas conductas que, trascendiendo del ámbito interno del partido, supongan una perturbación de la manifestación de la voluntad popular.

En mi opinión la posible tipificación autónoma del delito de financiación ilegal vendría justificada por las funciones que los partidos ejercen hacia los

${ }^{16}$ Nieto Martín, A., en Arroyo Zapatero, L.A. y Nieto Martin, A., (Coords.), Fraude y corrupción, op. cit., p. 123.

17 Maroto Calatayud, M., Corrupción y financiación de partidos políticos, op.cit., p. 378; GutiÉRrez RuBí, A., Temas para el Debate, nº 223, 2013, pp. 46 s. 
ciudadanos y que hace que los partidos políticos no tengan una naturaleza puramente privada y puedan obtener, por tanto, una protección reforzada.

\subsection{Bien jurídico protegido y aclaración de conceptos}

\subsubsection{Bien jurídico}

La cuestión más relevante por tanto es la de si se puede hablar de un bien jurídico penal merecedor de protección en las conductas de financiación ilegal de los partidos políticos ${ }^{18}$.

Los partidos políticos cumplen una función básica para el funcionamiento democrático del Estado: concurren a la formación y manifestación de la voluntad popular, por ello son expresión del pluralismo político e instrumentos fundamentales de participación política -art. $6 \mathrm{CE}-$ La principal función de los partidos será, por tanto aglutinar la voluntad popular para transformarla en voluntad del Estado a través de los órganos públicos representativos. Primero el partido político forma una voluntad programática unitaria. Posteriormente se concurre a expresar la voluntad popular definitiva en los órganos públicos representativos por medio de los representantes públicos seleccionados y presentados por los partidos políticos. Estas funciones pueden resumirse en una: la de ser los partidos los intermediarios entre la sociedad y el Estado $^{19}$. Esa formación y manifestación de la voluntad popular es lo que debe producirse libre de injerencias extrañas que busquen favorecer intereses y voluntades particulares frente a la voluntad programática. Y este será el bien jurídico protegido en el delito de financiación ilegal. Como afirma GARCÍA DE ENTERRÍA la democracia exige objetividad. El criterio de objetividad rige como criterio rector del comportamiento de la Administración hasta tal punto que si decae, el Estado y su aparato administrativo dejarán de ser democráticos. La corrupción hace que los sectores económicos sean los que impongan los reales programas políticos aunque no se publiciten ${ }^{20}$. De la misma manera, determinadas conductas de financiación ilegal pueden hacer que el real programa del partido político no sea el que verdaderamente se ofrece y al que los ciudadanos votan, produciéndose una perturbación grave de las funciones de formación y de manifestación popular.

¿Tiene este bien jurídico suficiente entidad para ser merecedor de protección penal? En mi opinión sí. Los partidos políticos son considerados hoy en día sujetos imprescindibles para el funcionamiento del Estado democrático

${ }_{18}$ Sobre el concepto de bien jurídico y de bien jurídico-penal, MIR PUIG, S., DPPG 9a, $2011,119$.

19 Bautista Plaza, D.J., La función constitucional del Estado, 2006, 16 ss.

${ }^{20}$ García de Enterría, E., Democracia, 5a , 2000, 123 ss. 
representativo, denominado por buena parte de la doctrina e incluso por el TC como un «Estado de partidos» $»^{21}$. Aunque formalmente el art. 23.1 CE dispone que los ciudadanos tienen derecho a participar directamente en los asuntos públicos, en la práctica las fórmulas para la participación directa son poco operativas en España debido a los rigurosos requisitos que se exigen, por lo que se puede afirmar que en nuestro sistema los partidos constituyen el principal y casi único vehículo de expresión política ciudadana ${ }^{22}$.

Es cierto que para que la formación y manifestación de la voluntad popular puedan configurarse correctamente son básicos dos elementos: la democracia interna dentro del partido y la transparencia. En cuanto al requisito de democracia interna, estoy de acuerdo con los que afirman que la profundización de la democracia pasa por democratizar el funcionamiento y organización interna de los partidos. La voluntad popular final no puede ser fruto de la concurrencia de voluntades de las oligarquías dominantes en los partidos, aunque sean ratificadas electoralmente. Los partidos deben elaborar democráticamente su voluntad programática para que la voluntad final pueda considerarse popular en su plenitud ${ }^{23}$. Además, estoy de acuerdo con que cuanto menor sea la democracia interna de los partidos, mayor será el riesgo de clientelismo, ya que cuanto menos democráticos sean los procesos internos del partido para la elección de cargos, confección de listas, etc. más dependerán los elegidos de los que ostentan el poder en el partido y mayor influencia podrán ejercer estos sobre aquellos ${ }^{24}$.

Dicho todo lo anterior, sin embargo, considero que la democracia interna en si misma no tiene suficiente entidad para ser reconocida como un bien jurídico penal, al menos autónomo. No creo que la perturbación de los procesos internos de los partidos políticos tenga entidad suficiente para constituir un injusto específico. Se puede hacer una equiparación entre los partidos políticos, como instituciones básicas en un sistema democrático, y la Administración pública. Igual que en el Título XIX no se protege a la Administración como institución en si misma, sino como un ente prestacional de servicios a los ciudadanos, en el caso de los partidos políticos tampoco se protegerán en si mismos, sino como entes que prestan a los ciudadanos un

${ }^{21}$ Ampliamente, Navarro Méndez, J.I., Partidos politicos, 1999, 238 ss. STC 3/1981, de 2 de febrero.

22 Por todos, Navarro Méndez, J.I., Partidos políticos, op. cit., $236 \mathrm{~s}$.

23 NAVARro MÉndeZ, Partidos políticos, 1999, 238 ss.; BAUtista PlazA, La función constitucional de los partidos políticos, 2006, 26 ss.; FLORES GIMÉNEZ, en: NIETO/MAROTO (dirs.), Prevención de la corrupción, 2014, 188 ss.

${ }^{24}$ Urquiza, Corrupción municipal, 2005, 174 s.; Maroto Calatayud, Corrupción y financiación de partidos políticos, 2012, 452 (Tesis Doctoral inédita); GuTIÉRREZ RuBí, Temas para el Debate 223 (2013), 46; Olaizola Nogales, La financiación ilegal de los partidos políticos, 2014, 205. 
servicio básico en una sociedad democrática, como es la representación de la voluntad popular, como instrumentos canalizadores de los intereses ciudadanos. Por tanto, si bien la democracia interna será un requisito funcional necesario para que la manifestación de la voluntad popular sea correcta, no considero que tenga la categoría de bien jurídico. Es decir, será necesario que la conducta para ser tipificada autónomamente vaya más allá de la lesión o puesta en peligro de la democracia interna.

Tampoco considero que la transparencia sea un bien jurídico digno de protección penal autónoma. La publicidad de los donantes y de las donaciones permite a los ciudadanos estar alerta acerca de las posibles desviaciones y abusos de poder que puedan presentarse en el futuro como contrapartida de las donaciones. Además la transparencia sirve para que los ciudadanos conozcan la opción política a la que votan y los intereses que puede representar y para proteger la democracia interna del partido, pues permite el control de las bases sobre sus dirigentes. Las medidas de transparencia son el mejor antídoto contra la financiación ilegal de los partidos políticos y contra la corrupción que se deriva de ella. Apuesto por una transparencia completa, continua y oportuna. Por supuesto tiene que haber mecanismos de vigilancia, de control y de sanción en caso de incumplimiento, ya hemos visto como la LOFPP mejora este aspecto.

Dicho esto, creo sin embargo que la transparencia en si misma no es un bien jurídico penal.

En mi opinión el auténtico peligro y la razón por la que la norma administrativa prohíbe las donaciones anónimas, exige además unos límites cuantitativos o prohíbe que las donaciones procedan de determinadas empresas es porque así se evita que los partidos políticos puedan, una vez alcanzada determinada cota de poder, favorecer los intereses privados de los donantes. De hecho, si lo que se protegiera fuera la transparencia no habría, por ejemplo, límites cuantitativos o no se prohibirían las donaciones provenientes de empresas con contrato con la Administración, etc., puesto que bastaría, para proteger la transparencia, que el ciudadano lo supiera. En mi opinión, las normas de transparencia son un instrumento necesario para evitar que las formaciones políticas se desvíen de su función de satisfacer los intereses generales a favor de satisfacer los intereses «del que paga».

Si se conoce la identidad de los donantes será más fácil controlar si se le favorece especialmente, pero además, no basta con eso, sino que se impone un límite cuantitativo para que ninguna formación política sea dependiente en exceso de ningún interés particular, sea de una persona física o de una persona jurídica.

Teniendo en cuenta lo anterior y entendiendo que el peligro que se debe conjurar es que los partidos favorezcan intereses particulares a cambio de las donaciones, en vez de representar la voluntad popular, la pregunta será dónde 
debe comenzar a intervenir el Derecho penal. Considero que para que el Derecho penal intervenga será preciso que se constate al menos un peligro cercano de favorecimiento de intereses particulares, en detrimento de la voluntad programática y/o popular ${ }^{25}$.

No cualquier conducta de financiación ilegal será merecedora de sanción penal, o al menos no cualquier conducta de financiación ilegal vendrá a integrar un posible delito autónomo de financiación ilegal.

\subsubsection{Aclaración de conceptos: financiación irregular, financiación ilegal y financiación corrupta}

Creo que es conveniente aclarar tres conceptos diferentes, que a veces se mezclan: financiación irregular, financiación ilegal y financiación corrupta.

En el trabajo que elaboré sobre la financiación ilegal de los partidos políticos explicaba ampliamente estos conceptos, asumiendo la definición que Malem SeÑa hacía de ellos. Según este autor, por financiación irregular debe entenderse determinadas estrategias utilizadas por los partidos para conseguir apoyo económico de forma no ortodoxa, pero sin infringir ninguna ley. Suelen ser supuestos en los que los partidos se aprovechan de lagunas legislativas ${ }^{26}$, así, por ejemplo, en la LO 8/2007 podrían constituir lagunas las posibles condonaciones de las entidades de crédito a los partidos o la falta de límites de las donaciones a las fundaciones. La financiación ilegal vendría integrada por los supuestos en los que se transgrede la ley. Por último, la financiación corrupta es aquella en la que quien recibe la donación en nombre del partido se compromete a tomar una decisión o a influir para que otros tomen una decisión en el sentido querido por el donante. El elemento necesario para la financiación corrupta es el quid pro quo, esto es, el intercambio de prestaciones entre el donante y el que recibe la donación ${ }^{27}$. La mayoría de los escándalos de financiación ilegal de partidos políticos han estado relacionados con la adjudicación de contratos públicos, de diversa índole, a cambio de las donaciones. En estos momentos, en el escándalo Gürtel, diversas empresas están siendo objeto de investigación por haber sido beneficiarias de contratos públicos supuestamente a cambio de las donaciones. Esta clasificación, en mi opinión muy clara, sirve para graduar distintas posibles responsabilidades.

En principio la financiación irregular no podrá llevar aparejada responsabilidad jurídica, aunque sí responsabilidad moral y ética y, en último término,

${ }^{25}$ Ampliamente, Olaizola Nogales, I., La financiación ilegal de los partidos politicos, op.cit., pp. 203 ss.

${ }^{26}$ Malem SeÑa, J. F., La corrupción, 2002, pp. 112 s.

27 Ibidem, pp. $114 \mathrm{~s}$. 
responsabilidad política. El hecho de que una determinada forma de financiación no sea ilegal, debido a una laguna, no quiere decir que sea correcta o éticamente aceptable. Creo que es importante deslindar las responsabilidades políticas de las jurídicas y/o penales ${ }^{28}$.

En segundo lugar, la financiación ilegal podrá llevar aparejada, como ya se ha visto en la primera parte del trabajo, una sanción administrativa en aquellos casos en los que se infringe la LOFPP, también podrá llevar aparejada una responsabilidad penal porque se haya infringido algún precepto del $\mathrm{CP}$, así, por ejemplo, porque se haya cometido un delito de falsedades, un delito contra la Hacienda Pública, un delito electoral, etc. e incluso algunos de estos supuestos con ciertos requisitos podrán constituir un delito autónomo de financiación ilegal.

Por último, la financiación corrupta será la que en mi opinión merezca siempre un reproche penal.

En mi opinión, la financiación corrupta se caracteriza por su carácter finalista, por lo que este tipo de financiación será en principio siempre ilegal, puesto que la LOFPP prohíbe en todo caso las donaciones finalistas.

Esta exigencia del quid pro quo es lo que puede perturbar la principal función de los partidos que es la representación de la voluntad popular. En primer lugar, porque la voluntad popular se sustituye por la voluntad del donante, quebrando así la posibilidad de que todos los ciudadanos puedan influir por igual en la actuación política a través de la regla de «una persona un voto», por valer más el voto del que «paga». En segundo lugar, porque las decisiones políticas no se tomarán atendiendo a las necesidades de los ciudadanos, sino atendiendo a en qué ámbitos de actuación puede haber más empresas dispuestas a pagar. Además, a la hora de tomar la decisión no se atenderá a criterios de competencia. En tercer lugar, porque estas decisiones no se explican a los ciudadanos ni a las bases del partido -quiebra de la democracia interna-, la corrupción hace que se oculten los verdaderos motivos por los que se toman aquellas -quiebra de la transparencia-. Debido al secre-

${ }^{28}$ Resulta interesante la reflexión que sobre este punto hace MARTínEz Cousinou, G., Documentos de Trabajo IESA 3, 2007, 17, $\mathrm{n}^{\circ}$ 19: «La exigencia de responsabilidades penales en lugar de políticas por los escándalos de corrupción fue la tendencia normal durante los años noventa. En teoría lo que se pretendía al enviar a la justicia penal los hechos de corrupción era evitar que se acusara sin gran fundamento, y evitar, por tanto, que se eliminara la presunción de inocencia, no obstante, en la práctica fue diferente: se terminó dejando la depuración de la responsabilidad política en manos de la Administración de Justicia. Con ello se dañaba la imagen de la judicatura como institución neutral en la lucha partidista y el funcionamiento de la democracia misma quedaba deteriorado». Esta autora se refiere a los años noventa, pero creo que se puede afirmar que la situación actual no dista en absoluto de aquella, lo que está generando un grado de decepción y de desconfianza cada vez mayor de los ciudadanos hacia la política. 
to que rodea a todo acto corrupto, dichas decisiones quedarán sustraídas del programa político que el partido publicite.

Ahora bien, en una propuesta de regulación penal, relacionada con la financiación ilegal entiendo que no sólo se deben tener en cuenta aquellos casos en los que haya un pacto ya consolidado con una contraprestación concreta, sino que se incluirán también aquellos casos en las que no habiendo un pacto concreto, sí que hay determinadas conductas anteriores (de engrasamiento) que tienen como finalidad última llegar a ese pacto.

Al hilo de estos conceptos es interesante añadir la definición que otros autores realizan de la financiación corrupta. Especialmente destaca la clasificación de VILLORIA MENDIETA ${ }^{29}$, que dentro de la financiación corrupta incluye tres situaciones diferentes: La financiación de captura, en la que a través de la financiación, sea legal o ilegal ${ }^{30}$, se capturan puestos relevantes o decisiones políticas o gubernamentales. Aquí, según ViLLORIA MENDIETA, la financiación supone un pago anticipado por la toma de decisiones que favorecerá al financiador. Es un acuerdo mutuo que beneficia tanto al financiador como al financiado. Entiendo que esta definición coincide con la financiación corrupta que indica Malem SeÑa, el acuerdo mutuo que menciona Villoria Mendieta, sería el pacto corrupto del que habla MALEM SEÑA ${ }^{31}$. En segundo lugar, la financiación ventajista sería aquella en la que el partido, aprovechando lagunas normativas o vulnerando la ley, trata de obtener ventajas sobre el resto de candidatos o de partidos. Según Villoria Mendieta, en estos casos no habrá captura porque los intermediarios en la financiación pueden realizar promesas a los financiadores, pero si el gobierno no se compromete no habrá captura. Como variantes de esta financiación este autor incluye: 1 . Actividades que desobedecen las normas existentes de financiación política; 2 . La aceptación de fondos provenientes de un delito; 3. Gastos ilegales en campaña; 4. El abuso de recursos estatales ${ }^{32}$. Según SANDOVAL, esta financiación ventajista serán casos de financiación irregular o ilegal para MALEM SEÑA, ya que se obtiene un beneficio extraposicional para el partido, pero sin que sus dirigentes se obliguen, en virtud de un pacto corrupto a realizar una determinada contraprestación que suponga un incumplimiento de su deber posicional ${ }^{33}$. En mi opinión, estos ca-

${ }^{29}$ Villoria Mendieta, M., La corrupción política, 2006, pp. 198 ss. En el mismo sentido, SANDOVAL, RGDP, 22, 2014, pp. 37 ss.

${ }^{30}$ En mi opinión esta financiación será siempre ilegal porque se tratará de donaciones finalistas y por tanto, sean del importe que sean, serán ilegales conforme a la LO 5/2012 de financiación de partidos políticos.

31 Villoria Mendieta, M., La corrupción politica, op.cit, pp. 197 s; en el mismo sentido SANDOVAL, RGDP, op.cit., p. 37.

32 Ibídem, pp. $199 \mathrm{~s}$

33 SANDOVAL, RGDP, op.cit., p.38. 
sos serán supuestos de financiación ilegal o irregular, y en algunos de ellos podría ocurrir que, por la reiteración de la conducta o por la enorme cantidad de dinero donado, se pueda afirmar que, aunque no se ha producido el pacto para una concesión concreta, hay un peligro cierto de que dicho pacto se produzca y en este sentido se puedan incluir estas conductas en el delito autónomo de financiación ilegal. Por último, en tercer lugar, dentro de la financiación corrupta, incluye VILLORIA MENDIETA la financiación coercitiva que supone la obtención de dinero por parte del partido mediante el uso de la extorsión y de la amenaza ${ }^{34}$. En mi opinión estos casos, más allá de que puedan encajar en un posible delito autónomo de financiación ilegal, habrá que castigarlos también por los posibles delitos contra la libertad que se hubieran dado ${ }^{35}$.

Estas clasificaciones sirven para aclarar conceptos, para diferenciar distintas situaciones y para valorar la respuesta política, jurídica o jurídica-penal que hay que dar en cada caso.

Como ya he indicado más arriba, entiendo que en una propuesta de regulación penal sobre financiación ilegal no sólo deberán incluirse casos en los que haya un pacto concreto y determinado -financiación corrupta en la concepción de MaLem SeÑA-, en cuyo caso, como se verá más adelante, soy partidaria de incluirlos dentro de los delitos contra la Administración, sino también aquellas conductas que por sus características puedan favorecer claramente la obtención de ese pacto en un futuro, para los que propongo un tipo autónomo y específico de financiación ilegal -algunos supuestos de financiación ventajista en la concepción de Villoria Mendieta. Otros supuestos de financiación ventajista, ilegal o coercitiva habrá que analizarlos casos por caso y la mayoría de ellos o bien supondrán una infracción administrativa o podrán ser integrados en otros tipos penales.

\subsection{Preceptos concretos y valoración crítica}

En la LO 1/2015, de 30 de marzo, se recoge un nuevo Título XIII bis que está integrado por los arts. 304 bis y 304 ter, con la siguiente rúbrica: «De los delitos de financiación ilegal de los partidos políticos».

Art. 304 bis: «1. Será castigado con una pena de multa del triplo al quíntuplo de su valor, el que reciba donaciones o aportaciones destinadas a un partido político, federación, coalición o agrupación de electores con infracción de lo dispuesto en el artículo 5.1 de la Ley Orgánica 8/2007, de 4 de julio, sobre financiación de los partidos políticos./ 2. Los hechos anteriores serán castigados con una pena de prisión de seis meses a cuatro años y multa

${ }^{34}$ Villoria Mendieta, M., La corrupción política, op.cit, pp. 200.

${ }^{35}$ Sería parecido a la diferencia entre el delito de cohecho y el delito de concusión. Sobre ello, Olaizola Nogales, I., El delito de cohecho, 1999, pp. 243 ss. 
del triplo al quíntuplo de su valor o del exceso cuando: a) Se trate de donaciones recogidas en el artículo 5.1, letras a) o c) de la Ley Orgánica 8/2007, de 4 de julio, sobre financiación de los partidos políticos, de importe superior a 500.000 euros, o que superen en esta cifra el límite fijado en la letra b) del aquel precepto, cuando sea ésta el infringido. b) Se trate de donaciones recogidas en el artículo 7.2 de la Ley Orgánica 8/2007, de 4 de julio, sobre financiación de los partidos políticos, que superen el importe de 100.000 euros./ 3 . Si los hechos a que se refiere el apartado anterior resultaran de especial gravedad, se impondrá la pena en su mitad superior, pudiéndose llegar hasta la superior en grado./ 4. Las mismas penas se impondrán, en sus respectivos casos, a quien entregare donaciones o aportaciones destinadas a un partido político, federación, coalición o agrupación de electores, por sí o por persona interpuesta, en alguno de los supuestos de los números anteriores./ 5. Las mismas penas se impondrán cuando, de acuerdo con lo establecido en el artículo 31 bis de este Código, una persona jurídica sea responsable de los hechos. Atendidas las reglas establecidas en el artículo 66 bis, los jueces y tribunales podrán asimismo imponer las penas recogidas en las letras b) a g) del apartado 7 del artículo 33.».

Art. 304 ter: 1. Será castigado con la pena de prisión de uno a cinco años, el que participe en estructuras u organizaciones, cualquiera que sea su naturaleza, cuya finalidad sea la financiación de partidos políticos, federaciones, coaliciones o agrupaciones de electores, al margen de lo establecido en la ley./ 2. Se impondrá la pena en su mitad superior a las personas que dirijan dichas estructuras u organizaciones./ 3. Si los hechos a que se refieren los apartados anteriores resultaran de especial gravedad, se impondrá la pena en su mitad superior, pudiéndose llegar hasta la superior en grado.»

Los preceptos son criticables tanto por razones de fondo como técnicas.

El primer párrafo del art. 304 bis recoge como conducta típica la pura infracción del art. 5.1 de la LO 8/2007. Habrá de entenderse que se trata del art. 5.1 modificado por la LO 3/2015 36 Por tanto eleva la infracción administrativa a delito sin exigir ningún elemento que dote de lesividad al precepto. Esto genera un doble problema. El primero de fondo, ya que el legislador se olvida de que entre el Derecho administrativo sancionador y el Derecho penal debe haber una diferencia, sino cualitativa, sí al menos cuantitativa que diferencie ambos tipos de infracciones. El segundo problema es de índole

${ }^{36}$ Art. 5.1 LO 3/2015: «Los partidos políticos no podrán aceptar o recibir directa o indirectamente: a) Donaciones anónimas, finalistas o revocables.

b) Donaciones procedentes de una misma persona superiores a 50.000 euros anuales.

c) Donaciones procedentes de personas jurídicas y de entes sin personalidad jurídica. Se exceptúan del límite previsto en la letra b) las donaciones en especie de bienes inmuebles, siempre que se cumplan los requisitos establecidos en el artículo 4.2, letra e)». 
práctico. Es decir, se plantea la cuestión de qué precepto será aplicable cuando un sujeto reciba una donación infringiendo el art. 5.1 LO 8/2007. Esto es, la duda será si se deberá aplicar el art. 17 bis de la misma ley, que impone una sanción administrativa o el art. 304 bis CP. No se puede deducir cuál será el criterio de distinción para aplicar un precepto u otro porque no establece ninguno y ello es insostenible. Pero además se plantea un problema añadido. En el párrafo 4 del art. 304 bis se indica que se impondrán las mismas penas, en sus respectivos casos, a quien entregare las donaciones. Como ya se ha analizado más arriba la legislación administrativa no sanciona al donante, por lo que éste responderá en todo caso por vía penal. Puede darse la paradoja de que el miembro del partido que recibe la donación sea sancionado por vía administrativa y el donante por vía penal. O que se considere que si el miembro del partido es sancionado por vía administrativa, la conducta del donante debe quedar impune.

En mi opinión el primer párrafo del art. 304 bis debe eliminarse y la conducta del donante en esos casos debe ser incluida como infracción administrativa.

En el segundo párrafo del art. 304 bis se incrementa la pena que será de prisión de seis meses a cuatro años y multa del triplo al quíntuplo de su valor o del exceso, atendiendo básicamente a la cantidad donada o recibida. Es el importe de la donación lo que va a diferenciar en estos casos las infracciones administrativas del delito. En mi opinión, el criterio de la cantidad donada puede ser un criterio acertado para la diferenciación. Entiendo que una cantidad excesiva puede favorecer «la captura» del partido o el pacto corrupto, lo que me parece criticable es que sea el único criterio.

Sin embargo, considero que este párrafo adolece de algunos defectos. El primero es que apostando por la técnica de la ley penal en blanco, se refiere únicamente al art. 5.1 de la LO 8/2007. Habrá que entender que será el art. 5.1 modificado por la LO 3/2015. Lo importante es que al referirse expresamente al art. 5.1 se olvida de otras posibles donaciones ilegales, así, por ejemplo, las condonaciones de las entidades de crédito -art. 4.4 LO 8/2007o por ejemplo las donaciones de personas físicas que tengan contrato en vigor con la Administración están prohibidas -art. 4.2 a) LO 8/2007 ¿será necesario que superen en 500.000 euros el límite fijado para el resto de personas físicas? Partiendo de que en algunos supuestos de tipificación de la financiación ilegal es necesario acudir a la técnica de la ley penal en blanco, me parece erróneo limitarse a citar un precepto de la ley administrativa. Probablemente hubiera sido mejor que en el precepto se hiciera una referencia general a la LO 8/2007. En la misma línea tampoco se entiende del todo por qué en el apartado b) del párrafo se incluyen las donaciones del art. 7.2 de la LO $8 / 2007$, referidas a donaciones provenientes de gobiernos o empresas públicas extranjeros y de empresas relacionadas directa o indirectamente con 
ellos, pero no se incluye el art. 7.1 LO8/2007, que se refiere a las donaciones privadas provenientes de personas físicas extranjeras, que están sujetas a los mismos límites que los nacionales, pero que parece que si sobrepasan el límite de los 500.000 euros no cometerán el delito. Lo que quiero decir es que si el criterio, para la consideración de estas conductas como delito, es el exceso de la donación, no se comprende por qué ese exceso sólo constituye delito en algunas ocasiones.

En todo caso lo que me parece más criticable de este precepto es que solo tiene en cuenta como criterio el exceso de la donación. En mi opinión una regulación completa sobre financiación ilegal debe empezar por distinguir los supuestos en los que se ve involucrada la Administración de los supuestos en los que no. Por ejemplo, el legislador se olvida de una cuestión trascendental y es, si tratándose de una cantidad que no llegue a los 500.000 euros, sin embargo sirve para pactar con el alcalde de una localidad una determinada adjudicación de una obra ¿bastará con la aplicación del delito de cohecho al alcalde y al donante? ¿Qué pasará con el miembro del partido que se limita a recibir la donación? ¿Bastará con la aplicación de un posible delito de blanqueo? ¿No se podrá aplicar un delito de financiación ilegal porque la cantidad no ha llegado a los 500.000 euros? Desde mi perspectiva, teniendo en cuenta que estos delitos no están pensados para proteger el orden socioeconómico, sino las funciones constitucionales de manifestación de la voluntad popular que tienen los partidos, el hecho de que esté o no involucrada la Administración debe ser un criterio decisivo para tener en cuenta en la regulación de estos comportamientos. En estos supuestos, como luego detallaré, no se debe acudir a la técnica de a ley penal en blanco, sino que en los delitos clásicos contra la Administración pública deberían preverse cláusulas que recogiesen aquellos supuestos en los que se ve favorecido un partido político a través de la conducta delictiva del funcionario público.

El párrafo tercero recoge una agravación, la pena se impondrá en su mitad superior, en los casos de especial gravedad. Dado que el único criterio tenido en cuenta para tipificar estas conductas es el de la cantidad, entiendo que la especial gravedad deberá referirse a que la cantidad sobrepase de manera muy importante las señaladas en el precepto.

El párrafo cuarto señala la responsabilidad penal del donante. El legislador considera que cualquier donación realizada, que vulnere el art. 5.1 de la LO 8/2007 de financiación de partidos, constituye delito para el donante. Esto es, la conducta del donante en ningún caso, como se ha visto, se considera infracción administrativa, tal y como venía siendo recomendado por el GRECO, y sin embargo prácticamente todas las donaciones efectuadas ilegalmente van a constituir infracción penal. Además el párrafo señala que el donante puede entregar la donación por sí o por persona interpuesta. Probablemente el legislador esté pensando en los supuestos en los que para ocultar 
la donación se utilice a un tercero, queriendo sancionar de este modo conductas de ocultamiento, pero se olvida de otras formas de ocultamiento como, por ejemplo, el fraccionamiento de la donación.

El párrafo quinto recoge la posible responsabilidad de la persona jurídica. En este caso tanto la posible responsabilidad del partido político, puesto que a través de la reforma por LO 7/2102, de 27 de diciembre, en materia de transparencia y lucha contra el fraude fiscal y en la Seguridad Social, se introdujo la responsabilidad de partidos políticos y sindicatos en el régimen general de responsabilidad de las personas jurídicas, como también se aplicará este párrafo a la responsabilidad de la persona jurídica donante.

En cuanto al art. 304 ter se trata de un precepto muy indeterminado. En el primer párrafo se castiga la participación en estructuras u organizaciones de cualquier naturaleza cuya finalidad sea la financiación ilegal de partidos políticos. Debería acotarse qué se entiende por participar. El precepto eleva literalmente la participación a conducta de autoría sin ninguna restricción ¿qué entenderemos por participar? ¿A qué se refiere el precepto con estructuras u organizaciones? ¿Deben tener carácter estable? ¿Dará igual la relevancia de la participación? ¿Será indiferente que sea puntual o habitual?

Tampoco aclara el precepto si la finalidad de financiar ilegalmente a un partido político debe ser la única finalidad de la organización o puede tener más finalidades y además la de financiar ilegalmente a un partido. Entiendo que será más adecuada la primera opción, puesto que de esa manera se estará sancionando a aquellos que intervengan en empresas pantalla o falsas -caso Filesa- cuyo único propósito es conseguir financiación ilegal.

No queda claro tampoco la posible relación concursal entre ambos preceptos. Es decir cómo se resolverán los casos en los que el miembro del partido que recibe las donaciones ilegales participa también en una estructura con dicha finalidad. Por otro lado, para que la conducta del art. 304 bis sea delictiva deben sobrepasarse determinadas cantidades, mientras que no se exige esto en el 304 ter que sólo se exige la participación en una estructura que tenga por finalidad la consecución de donaciones ilegales.

Tampoco acabo de ver el fundamento por el que el art. 304 ter prevé una pena superior al 304 bis.

En el párrafo segundo se impone la pena en su mitad superior a las personas que dirijan dichas estructuras u organizaciones y en el párrafo tercero se prevé otra agravación, pudiendo incluso llegarse a la pena superior en grado, cuando los hechos revistan especial gravedad. En este caso no resultará fácil averiguar cuándo estaremos ante hechos de especial gravedad porque no queda claro cuál es el fundamento del precepto. Probablemente dentro de los criterios posibles estará el de la mayor o menor relevancia de la organización: cantidad de personal, ámbito espacial de actuación, estabilidad de la organización, tiempo de funcionamiento, etc. 
Como conclusión sobre estos preceptos se puede decir que adolecen de defectos tanto de carácter formal como de fondo. Creo que se han introducido sin tener una idea clara de lo que intenta proteger con ellos y de qué conductas se quieren evitar. Considero que es una reforma hecha sin la suficiente reflexión.

\section{PROPUESTA PERSONAL DE REGULACIÓN PENAL}

En otro trabajo, ya publicado, expliqué con detalle cuál era, a mi modo de ver, la mejor propuesta de regulación penal sobre la financiación ilegal de los partidos políticos ${ }^{37}$. Por ello, en este caso, me limitaré a dar las pautas generales que propongo.

\subsection{Supuestos en los que se ve involucrada la Administración}

El criterio rector de la legislación que se propone se basa en diferenciar los casos de financiación en los que se ve involucrada la Administración Pública de aquellos en los que no. En los supuestos en los que se ve involucrada la Administración pública, los tipos penales de cohecho y tráfico de influencias pueden ser adecuados para responder frente a algunos casos de financiación corrupta, entendida esta como aquella financiación de partidos políticos en la que el donante busca una contraprestación concreta. La inclusión de los partidos políticos como posibles personas jurídicas responsables penalmente, hace que en muchos de los supuestos de financiación corrupta puedan responder los partidos.

Se pueden destacar, no obstante, algunos problemas relativos a la aplicación de estos delitos. Así, cuando se trata del delito de cohecho nos encontramos con que cuando el partido es el mero receptor del beneficio, esto es, el destinatario de la donación, no se le puede responsabilizar penalmente por este delito, por lo que podrá responder el donante y el cargo público, pero no el cargo del partido ni el propio partido. En estos casos cabría la posibilidad de aplicar el delito de blanqueo de capitales, pero en mi opinión el delito de blanqueo no es suficiente para recoger todo el desvalor de la conducta. En la vida real el partido político no es un mero receptor de la dádiva, sino que desde las cúpulas de los partidos se deciden las listas electorales, de ellos dependen qué personas van a ocupar los cargos públicos. Cuando el cargo público solicita una comisión a una empresa a cambio de, por ejemplo, la adjudicación de un contrato público y dicha dádiva toda o en parte la ingresa en las cuentas del partido lo hace porque sabe que ello repercutirá a futuro en su carrera política,

37 Olaizola Nogales, I., La financiación ilegal de los partidos politicos, op.cit., pp. 197 ss. 
sabe que el partido «se lo agradecerá» a él y a la empresa que ha realizado la donación. A su vez, se produce un peligro para el correcto ejercicio de las funciones constitucionales que los partidos cumplen hacia los ciudadanos, el peligro de ser finalmente capturados por sus donantes. En mi opinión, este desvalor no queda recogido con la única aplicación del delito de blanqueo ${ }^{38}$.

Tampoco se puede apreciar el delito de cohecho cuando se producen donaciones de «forraje» al partido político sin que se pueda demostrar que dicha donación llega a un cargo público, bien como cohecho de facilitación, o para una contraprestación concreta. Podrían ser supuestos de «financiación ventajista». Se trata de casos en los que no se produce la relación quid pro quo, que es básica en los delitos de cohecho y de tráfico de influencias. Son casos en los que las empresas van realizando donaciones al partido político -donaciones anónimas o que sobrepasan la cantidad legal permitida-con el fin de crear buen clima que permita a la empresa salir favorecida en un futuro. Estos casos, con algunos requisitos, podrán configurar un delito autónomo de financiación ilegal.

Cuando se trata del delito de tráfico de influencias el problema reside en que estos tipos no recogen la mera conducta de influir con prevalimiento, sino que esa influencia tiene que dirigirse a la consecución de una resolución injusta, por lo que aquellos casos en los que la influencia busque otra clase de actuación administrativa quedarán fuera de estos tipos penales.

Además, en los supuestos en los que se pueda aplicar el delito de tráfico de influencias nos encontramos con dificultades para hacer responder al donante, que en algunos casos sólo podrá responder como inductor y en otros no responderá. Así por ejemplo los supuestos en los que un cargo de un partido político solicita a una empresa una donación a cambio de interceder a su favor ante un cargo público ${ }^{39}$.

En mi opinión, en los casos de financiación ilegal de partidos políticos en los que se ve involucrada la Administración, además de verse perturbado el correcto funcionamiento de la Administración pública, protegido en el Título XIX del CP, se pone en peligro el correcto ejercicio de la función constitucional de formación y manifestación de a voluntad popular, por ello abogo por añadir en los delitos de cohecho, de tráfico de influencias y de malversación cláusulas que agraven la pena y la eleven a su mitad superior ${ }^{40}$. Con la

${ }^{38}$ Desde luego el delito de blanqueo es un delito clave en los supuestos de financiación ilegal de partidos. No hay más que comprobar las investigaciones del caso Gürtel para ver la importancia del delito de blanqueo.

39 Sobre estos problemas extensamente, Olaizola Nogales, I., La financiación ilegal de los partidos políticos, op.cit., pp. 142 ss.

40 Ampliamente, Olaizola Nogales, I., La financiación ilegal de los partidos politicos, op.cit., pp. 197 ss. Añadir en los arts. 419, 420, 421 y 422 -delitos de cohecho pasivo- las siguientes cláusulas: 
introducción de estas cláusulas en los delitos actualmente vigentes queda clara la tipicidad de la financiación ilegal, el carácter pluriofensivo de estas conductas y no habrá riesgo de que la tipificación autónoma lleve a una sanción penal inferior de estos supuestos.

Con esta propuesta quedan tipificadas las conductas de financiación ilegal más graves. Aquellas en las que se ve involucrada la Administración y que por tanto tienen un carácter pluriofensivo. En los supuestos de delitos de cohecho y de tráfico de influencias se trata de donaciones finalistas y constituyen por tanto supuestos de financiación corrupta.

\subsection{Supuestos en los que no se ve involucrada la Administración}

Para estos casos se propone un tipo penal específico de financiación ilegal de partidos políticos ubicado en el Título XXI entre los delitos contra la Constitución, puesto que se protege como bien jurídico protegido la función que ejercen los partidos políticos hacia los ciudadanos, formando y representando la voluntad popular. Se trata de evitar las conductas que puedan suponer un peligro para este bien jurídico por acercar la posibilidad de un pacto corrupto, aunque dicho pacto no se llegue a producir efectivamente. La pena, que no he concretado deberá ser en todo caso inferior que las que sancionan los supuestos en los que se ve involucrada la Administración.

Sigo en parte las propuestas realizadas por NIETO MARTín y por MAROTO CALATAYUD ${ }^{41}$, aunque con bastantes matices. La redacción concreta que se propone es:

«La pena se impondrá en su mitad superior cuando la dádiva, el regalo, o la retribución estén destinados total o parcialmente a favorecer a un partido político.

Con la misma pena será sancionado quien en nombre o por cuenta del partido reciba o acepte las ventajas a las que se refiere el apartado anterior».

Añadir en los arts. 429 y 430 -delitos de tráfico de influencias- las siguientes cláusulas

Art. 429: «La pena se impondrá en su mitad superior cuando el autor del delito sea un cargo de un partido político y busque con su conducta una resolución que pueda generar directa o indirectamente un beneficio económico al partido».

Art. 430: «La pena se impondrá en su mitad superior cuando la solicitud de la dádiva, del presente o de cualquier otra remuneración provenga de un cargo de un partido político y la dádiva, el presente o la remuneración tenga como destino total o parcialmente el partido político».

Añadir en los arts. 432 y 433 -delitos de malversación- la siguiente cláusula

«La pena se impondrá en su mitad superior cuando el destino de los caudales sustraídos sea un partido político. Con la misma pena responderá quien en nombre o por cuenta de un partido político reciba o acepte los caudales públicos sustraídos».

${ }^{41}$ Nieto Martín, A., en Arroyo Zapatero, L.A. y Nieto Martin, A., (Coords.), Fraude y corrupción, op.cit., pp. 128 ss.; MAROTO CALATAYUD, M., Corrupción y financiación de partidos políticos 2012, pp. 387 ss. (Tesis doctoral inédita). Ampliamente ex- 
1. «Será sancionado con...quien con el fin de ocultar su identidad, la cuantía de una donación o cualquier otro beneficio económico, de forma contraria a la regulación relativa a la financiación de partidos políticos y de manera reiterada (aquí cabría indicar el número de veces), a favor de una formación política:

a) fragmente la donación que efectúa o utilice una persona interpuesta

b) suministre datos falsos o incorrectos a la persona encargada legal o estatutariamente de llevar la contabilidad del partido político.

No se exigirá que la conducta sea reiterada, bastando con que se realice una única vez, cuando la cuantía de la donación supere de manera muy notable (aquí se puede dar una cantidad concreta de superación) la cantidad legal permitida.

2. Con la misma pena se sancionará a quien, en nombre o por cuenta del partido, solicite o acepte de forma reiterada (aquí se puede indicar el número de veces), de un mismo donante, donaciones que no cumplan la regulación relativa a la financiación de partidos políticos.

No se exigirá que la conducta sea reiterada, bastando con que se realice una única vez, cuando la donación solicitada o aceptada supere de manera muy notable (aquí se puede dar una cantidad concreta de superación) la cantidad legal permitida.

3. Será sancionado con...el encargado legalmente de efectuar la contabilidad del partido político o cualquier otra documentación o comunicación que realice de forma reiterada (aquí cabría indicar el número de veces) anotaciones o comunicaciones incorrectas o fuera del plazo establecido, a favor de un mismo donante, con el fin de ocultar la existencia de una donación, su cuantía, la identidad del donante o cualquier otro beneficio económico, de forma contraria a la regulación relativa a la financiación de partidos políticos.

No se exigirá que la conducta sea reiterada, bastando con que se realice una única vez, cuando la donación supere de manera muy notable (aquí se puede dar una cantidad concreta de superación) la cantidad legal permitida.

4. Será sancionado con...el auditor de cuentas o cualquier otra persona encargada del control externo de la financiación o situación patrimonial del partido político que informe incorrectamente o silencie circunstancias relevantes con el fin de ocultar la existencia de una donación, su cuantía, la identidad de un donante o cualquier otro tipo de relación económica entre el partido y terceras personas.

pongo y explico los matices a estas propuestas en Olaizola Nogales, I., La financiación ilegal de los partidos políticos, op.cit., pp. 193 ss. 
En el primer párrafo se tipifican conductas de ocultamiento. El ocultamiento por sí solo puede constituir una infracción administrativa, pero la reiteración de estas conductas a favor de una misma formación política o la elevada cuantía de la donación suponen un mayor acercamiento del peligro de favorecimiento para dicho donante, en definitiva un mayor peligro de que la formación política se vea «atrapada» por dicho donante. Debe tenerse en cuenta que se elimina el quid pro quo que se exige, con carácter general en el delito de cohecho o en el tráfico de influencias, por ello, a cambio, se propone la inclusión del requisito de la reiteración o de la cuantía que acercan el peligro.

Propongo la introducción de un párrafo segundo en el que se sancione al miembro del partido que en nombre o por cuenta del partido acepte de forma reiterada las donaciones o cuando, aun siendo una única donación, esta sobrepase de manera muy importante el límite recogido en la Ley de financiación de partidos políticos.

Igual que en el supuesto anterior la lesividad penal de esta conducta provendrá de la reiteración o de la cuantía de la donación.

Debo advertir que a diferencia del primer párrafo, en el que se exigen conductas concretas de ocultamiento, esto es, no basta con que se efectúen, aunque sea reiteradamente, donaciones ilegales, en el segundo párrafo se sanciona la solicitud o la aceptación de la donación por el cargo del partido, sin que sean precisas conductas de ocultamiento. En mi opinión, ello es coherente con la mayor exigencia a los partidos (representados por sus cargos) que a los particulares donantes, porque son los primeros los que tienen encomendadas directamente las funciones constitucionales de representación y manifestación de la voluntad popular. Por otra parte, el plus de lesividad que distingue a esta conducta, propuesta en el segundo párrafo, de la infracción administrativa correspondiente, radica en la exigencia de reiteración o en la cuantía.

En el tercer párrafo se tipifica una conducta de falsedad en la que el peligro proviene de nuevo de la reiteración de la conducta o de la cuantía de la donación. La falsedad tiene como finalidad las conductas de ocultamiento previstas en el primer párrafo. Probablemente estas conductas podrían constituir, en muchos casos, supuestos de participación de las conductas descritas en los párrafos primero y segundo, pero creo que no es incorrecta la tipificación expresa en un párrafo distinto por la importancia que tiene la tarea de los encargados del control interno del partido. Esta regulación expresa supone también incidir en la importancia que la transparencia tiene en este ámbito.

En el cuarto párrafo se incluye la sanción penal para el encargado del control externo que informa incorrectamente o silencie circunstancias relevantes. A diferencia de los casos anteriores, en este supuesto el autor es un sujeto ajeno a la formación política y goza por ello de una especial confianza por parte de las autoridades públicas de control, por ello no creo necesario introducir mayores requisitos. 
TITLE: 'Measures of democratic regeneration'. The new regulation of the funding system of political parties in Spain.

RESUMEN: La financiación de los partidos politicos es todavía hoy un problema sin resolver en nuestro país. Dentro de las medidas de regeneración democrática lanzadas por el gobierno se incluye la reforma de la regulación sobre la financiación de los partidos politicos. Concretamente, la reforma se concreta en dos normas relacionadas con nuestro modelo de financiación. Una de ellas de carácter administrativo y otra de carácter penal. En este trabajo trato de analizar ambas regulaciones y valoro las ventajas e inconvenientes, que desde mi punto de vista, tienen de cada una de ellas.

PALABRAS CLAVE: partidos políticos, financiación, corrupción, norma administrativa, norma penal.

ABSTRACT: Today, the control of the financing of political parties is still an unresolved problem in our country. The democratic revitalisation measures launched by the government include the reform of the regulation on the financing of political parties. Specifically, two regulations related to our financing model are currently being processed. One is of an administrative character whilst the other is of a criminal character. In this work, I endeavour to analyse both regulations and to assess, from my point of view, the strengths and weaknesses of each regulation.

KEY WORDS: political parties, financing, corruption, administrative rule, criminal legislation. 